\title{
Measuring and Detecting Errors in Occupational Coding: an Analysis of SHARE Data
}

\author{
Michele Belloni ${ }^{1}$, Agar Brugiavini ${ }^{1}$,Elena Meschi ${ }^{1}$, and Kea Tijdens ${ }^{2}$
}

This article studies coding errors in occupational data, as the quality of this data is important but often neglected. In particular, we recoded open-ended questions on occupation for last and current job in the Dutch sample of the "Survey of Health, Ageing and Retirement in Europe" (SHARE) using a high-quality software program for ex-post coding (CASCOT software). Taking CASCOT coding as our benchmark, our results suggest that the incidence of coding errors in SHARE is high, even when the comparison is made at the level of one-digit occupational codes ( $28 \%$ for last job and $30 \%$ for current job). This finding highlights the complexity of occupational coding and suggests that processing errors due to miscoding should be taken into account when undertaking statistical analyses or writing econometric models. Our analysis suggests strategies to alleviate such coding errors, and we propose a set of equations that can predict error. These equations may complement coding software and improve the quality of occupational coding.

Key words: ISCO; coding software; coding error; cognitive functioning; education.

\section{Introduction}

Knowledge concerning the occupations of individuals is important in many fields of the social sciences. For example, in economics, sociology, and other disciplines, occupation is

1 Department of Economics, Ca' Foscari University of Venice. S. Giobbe, Cannaregio, 87330121 Venice, Italy. Emails: michele.belloni@unive.it, brugiavi@unive.it, and elena.meschi@unive.it

${ }^{2}$ University of Amsterdam/Amsterdam Institute for Advanced Labour Studies (AIAS), Nieuwe Prinsengracht 130, 1018 VZ Amsterdam, Netherlands. Email: k.g.tijdens@uva.nl

Acknowledgments: This article builds on research carried out for the DASISH project (Data Service Infrastructure for Social Sciences and Humanities, funded by EU-FP7, Contract no. 283646) and the SHARE project (Survey of Health, Ageing and Retirement in Europe). The authors are grateful to researchers at CentERdata in the Netherlands for their efforts in coding Dutch job titles. The authors would like to thank Eric Balster, Peter Elias, Eric Harrison, Maurice Martens, Sue Westerman, and all participants of the "CASCOT: Occupational Coding in Multi-national Surveys" Workshop in Venice (10-11 April 2014) for helpful suggestions on earlier draft of this work. The research leading to these results has received support under the European Commission's 7th Framework Programme (FP7/2013-2017) under grant agreement $n^{\circ} 312691$, InGRID Inclusive Growth Research Infrastructure Diffusion. The last author would like to acknowledge the contribution of WEBDATANET [COST Action IS1004]. This paper uses data from SHARE wave 1 release 2.5.0, as of 23 August 2011. The SHARE data collection has been primarily funded by the European Commission through the 5th Framework Programme (project QLK6-CT-2001-00360 in the thematic programme Quality of Life), through the 6th Framework Programme (projects SHARE-I3, RII-CT-2006-062193, COMPARE, CIT5-CT-2005028857, and SHARELIFE, CIT4-CT2006-028812) and through the 7th Framework Programme (SHARE-PREP, $\mathrm{N}^{\circ}$ 211909, SHARE-LEAP, $\mathrm{N}^{\circ} 227822$ and SHARE M4, $\mathrm{N}^{\circ}$ 261982). Michele Belloni is also affiliated with CeRP - Collegio Carlo Alberto. Additional funding from the U.S. National Institute on Aging (U01 AG0974013S2, P01 AG005842, P01 AG08291, P30 AG12815, R21 AG025169, Y1-AG-4553-01, IAG BSR06-11 and OGHA 04-064) and the German Ministry of Education and Research as well as from various national sources is gratefully acknowledged (see www.share-project.org for a full list of funding institutions). 
often considered - either in itself or as part of an index - as a proxy for socioeconomic status. In sociology and labour economics, occupation is a key variable in a wide range of studies, such as the 'task approach' to labour markets and job polarisation (e.g., Autor 2013; Autor et al. 2006; Goos and Manning 2007); the definition of skill mismatch and overeducation (for an extensive overview of this literature, cf. e.g., Hartog 2000; Leuven and Oosterbeek 2011); the analysis of the effect of occupation on health status (e.g., Fletcher et al. 2011; Ravesteijn et al. 2013); the dynamics of occupational mobility (e.g., Moscarini and Thomsson 2007; Perales 2014); and the analysis of socioeconomic status (e.g., Rose and Harrison 2007).

The quality of occupational data is rarely discussed in this literature, despite the fact that the measurement of occupation in social surveys is a rather complex issue. Handbooks by international institutions such as the International Labour Organization (ILO) detail how to ask about occupation in labour force surveys and censuses (e.g., ILO 2010). However, empirical research on best practices and miscoding is scarce. The difficulty of providing researchers with an accurate measure of occupation concerns, first, the choice of questions to include in the questionnaire, second, the training of interviewers and, third, the conversion of job titles and descriptions that are often recorded in open text fields into occupational codes.

The statistical agencies of 150 countries associated with the ILO have adopted the International Standard Classification of Occupations (ISCO) to normalise the measurement of occupations. The first classification dates back to 1958, with updates in 1968, 1988, and recently in 2008. The Commission of the European Communities (2009) has adopted ISCO-08 as its occupational classification standard, and the European statistical agency Eurostat has made efforts to support European countries to develop coding indexes for occupation data collected through their own labour force and similar surveys. In 2012, almost half of the 150 countries associated with the ILO used the ISCO standard, while the other half either did not classify occupations or maintained their own classification standard (UN 2014).

The ILO provides a classification standard as well as task descriptions for all four-digit occupational units in ISCO (ILO 2014). The task descriptions also provide a coding index, but only in English. Therefore, the coding of occupations becomes particularly challenging in international surveys - such as the "Survey of Health, Ageing and Retirement in Europe" (SHARE) and the "European Social Survey" (ESS), where the occupational codes should be fully comparable across countries - because it is sometimes problematic for countries to map their specific occupations and job titles onto the international ISCO categories.

Researchers are often not aware of the complex preparatory work behind occupational coding, and often consider the published variable of 'occupation' as free of error. This is not the case if processing errors arise during the coding of the variable. Processing errors are one source of nonsampling errors that contribute to total survey errors (see Biemer and Lyberg 2003). Processing errors arise during the data-processing stage and comprise editing errors, coding errors, data-entry errors, and programming errors. For example, in coding answers to open-ended questions related to economic characteristics - such as occupation - coders may deviate from the procedures laid out in coding manuals and therefore assign wrong codes to these characteristics. 
Elias (1997) highlighted possible sources of error in occupational data, surveying the few existing studies that evaluated the quality of occupational data through recoding. $\mathrm{He}$ found that agreement rates (i.e., the percentage of verbatim responses coded equally after recoding) increased with higher levels of aggregation, thus at one or two digits. At three digits, agreement rates in excess of $75 \%$ were hard to obtain. Ellison (2014) pointed out that agreement rates tend to be higher for mother's, father's and last jobs than for an individual's current job. The intuitive explanation for these results is that individuals tend to give too many details about their current job because they think that their job is complex and thus do not provide a simple description, while this occurs to a lesser extent for parents' and last job.

In this article, we will first demonstrate that occupational coding is in fact susceptible to processing errors. In addition, we will test whether such processing errors are random or correlated to some specific individual or job-related characteristics. Finally, we will present our recommendations for reducing this type of error and will propose a novel predictive equation for coding error, given some individual and job-related characteristics, which may be particularly useful if used during interviews.

To attain our aims, we conducted the following empirical analysis. First, we recoded the verbatim response to the open-ended questions on current and last occupation for the Dutch sample of SHARE data using a well-known and high-quality software program for ex-post coding called CASCOT. Second, we compared SHARE data as originally published with recoded occupational variables. Finally, we analysed which individual and job-related characteristics (such as age, gender, education, or industry) were associated with the probability of coding error. The article proceeds as follows: Section 2 discusses the alternative methods used to collect and code information on individuals' occupations and describes the main features of CASCOT. In Section 3, we describe our empirical study and present the data and the methodology adopted. The results of our analysis are presented and discussed in Section 4. Finally, Section 5 presents our conclusions and suggests some directions for further research.

\section{Coding Occupations in Survey Data: Alternative Methods}

Most occupational information in survey data is obtained from direct questions addressed to respondents. The question about occupation is usually asked in an open text field (e.g.,: 'What occupation did you perform in your principal job during the week of . . . to . . . ?'; for an overview of survey questions see Tijdens 2014b; for question design see Jackle 2008 and DESA 2010). Open-ended questions allow the classification of occupations at a detailed level of disaggregation, but the text fields require coding afterwards ('office coding'). Promising attempts to code job titles during CAPI interviews are currently being made using a look-up table or coding index. One notable example of these new coding methods is the semantic text-string matching algorithm (the 'Jobcoder') developed by CentERdata (http://www.centerdata.nl/) and used for the first time in SHARE Wave 6. The occupational coding process in this wave of SHARE followed a two-step approach. In the first step, verbatim responses to the open-ended question on occupation were stored for future possible checks. In the second step, the verbatim responses were forwarded to the 'Jobcoder', which searched its job titles database and checked whether there was an entry 
that corresponded precisely. If such an entry was found, the software coded the text immediately; otherwise, the interviewer was given the opportunity to ask the interviewee for a more precise job description.

In the more standard case of 'office coding', the classification of occupational information is achieved after the interview through a coding process that can be done manually or semi-automatically using a computerised coding system ("computer-assisted coding') or by a combination of both. Manual coding requires a lot of training for coders and coder supervisors (see Hoffmann et al. 1995; Ganzeboom 2008). Semiautomatic coding tools are becoming increasingly reliable instruments that use semantic matching with previously coded occupations. Machine-learning algorithms also appear to be a promising recent development, requiring a substantial number of manually coded occupations to be used as training data for the automatic classification (Bethmann et al. 2014; Cheeseman Day 2014).

CASCOT is a software tool for coding text automatically or manually (http://www2. warwick.ac.uk/fac/soc/ier/software/cascot/). It was developed at the Institute for Employment Research (IER) in 1993 and since then has been continuously updated and used by over 100 organisations in the UK and abroad. The software developed at IER is able to code job titles in the UK into various editions of the Standard Occupational Classification (SOC) and International Standard Classification of Occupations (ISCO). CASCOT software is coupled with an editor which allows users to modify internal coding rules and permits the software to use alternative occupational classification structures. High-quality coding requires high-quality job descriptions. The recorded text should ideally contain sufficient information to distinguish it from alternative text descriptions which may be coded to other categories within the classification, but it should not contain superfluous words. The recorded text should also be free of typing errors if possible. This ideal will not always be achieved, but CASCOT has been designed to perform a complicated analysis of the words in the text, understand common typing errors and compare these words to those in the classification, ultimately providing a list of recommended codes. If the input text is not sufficiently distinctive, the topmost recommendation may not necessarily be the correct code. When CASCOT assigns a code to a piece of text, it also calculates a score from 1 to 100 , which represents the degree of certainty that the given code is the correct one. When CASCOT encounters a word or phrase that is descriptive of an occupation but lacks sufficient information to distinguish it from other categories (i.e., without any further qualifying terms), CASCOT will attempt to suggest a code but the score will be limited to below 40 to indicate the uncertainty associated with the suggestion (e.g., cases such as 'Teacher' or 'Engineer').

The user may run CASCOT in three different modes: fully automatic, semiautomatic, or manual/one-by-one. The fully automatic mode does not require any human intervention: once a list of job descriptions is provided in the software, a series of corresponding codes plus the associated scores is produced. If the software considers the quality of a given job description too low to be able to attribute any reasonable code, it reports 'no conclusion' for that specific text. The semiautomatic mode works by setting a minimum score: in all cases in which CASCOT attributes a score greater than the minimum value, it codes the text automatically; otherwise it asks for human intervention. In these cases, the operator is asked to choose manually from a list of recommendations. The operator's decision may be 
supported by ancillary variables if they are available in the data: a pop-up window opens in CASCOT and shows, for example, the industry in which the individual is/was working. In manual mode, CASCOT provides a list of recommended codes with corresponding scores for each job description, and leaves the final choice of the best code to the operator.

CASCOT output was compared to a selection of high-quality manually coded data, with the overall results showing that $80 \%$ of the records receive a score greater than 40 and, of these, $80 \%$ are matched to manually coded data. When using CASCOT, one can expect this level of performance with similar data, but the performance depends on the quality of the data input (for more information about the software, see Elias et al. 1993; Jones and Elias 2004).

Statistics Netherlands (CBS) has developed a Dutch version of CASCOT, building on the English version. Since 2012, this software (henceforth CASCOT-NL) has been used in the Netherlands to code job titles in the most relevant social surveys, including the Dutch Labour Force Survey. CASCOT-NL is suitable for implementation in CAPI, CATI, and CAWI modes.

In this study, we use a version of CASCOT-NL that was used by CBS to classify job descriptions given in the Dutch Labour Force Survey into four-digit ISCO-08 codes. A noticeable difference between CASCOT-UK and CASCOT-NL (the 'classification file ISCO v1.1') is that the latter includes a special category for vague responses called '99'. Very often, a certainty score equal to 99 is given to these cases originally coded ' 99 '. This is because - once tagged in this way - these especially problematic answers go through subsequent coding steps. These steps exploit information from additional variables such as sector of work, the individual's educational attainment and tasks and duties involved in the job. Finally, the most difficult cases are manually coded by a team of experts (see CBS 2012 and Westerman 2014 for further details on CBS coding procedures).

\section{Data and Empirical Strategy}

Our analysis is based on SHARE data. SHARE is a cross-national longitudinal survey on health, socioeconomic status and social and family networks representative of the population aged 50 and over. Four waves of SHARE are currently available. We focus on the first wave of data (collected in 2004-2005) because this is the only one in which information on occupation was gathered using an open-ended question (in the subsequent waves 2 to 5, the occupation question uses a tick list of ten occupational titles). In particular, in SHARE Wave 1, respondents were asked the following question: "What [is/was] your [main/last] job called? Please give the exact name or title." This question was directed at both employed/self-employed and retired/unemployed individuals (the latter conditional on having worked earlier in life). Note that SHARE also collects information on respondents' second job, parents' job and former partner's job. Parents' jobs are intrinsically more difficult to code than respondents' jobs because the former may have been excluded from recent job classifications. There are very few observations for respondents' second job and former partner's job. Thus we excluded these additional variables from our analysis.

SHARE country teams manually coded the text strings on respondents' job titles using ISCO-88 (COM) codes - the International Standard Classification of Occupations used at 
that time. Each country team hired and trained coders independently. Coders were asked to follow a protocol providing them with guidelines on how to code 'critical' jobs (e.g., managers in agriculture or teachers). These guidelines were partly common to all countries and partly language specific. SHARE coders also made use of ancillary information on training and qualifications needed for the job and on the industry the respondent was working in based on the question: "What kind of business, industry or services do you work in (that is, what do they make or do at the place where you work)?" SHARE coders were asked to code job descriptions at the maximum possible level of detail, that is, at four-digit (or Unit group) ISCO-88 level. It was also suggested that they code vague responses by means of trailing zeros: this means that if they were unsure whether a given job description could be attributable to a given Unit group, they should attribute it to either a Minor (i.e., three digits), Sub-major (two digits) or Major (one digit) group. The ISCO88 codes generated for two variables - one for current main job (ep016_) and one for last job (ep052_) - were then published (for further details, see MEA 2013, 29). The first wave of SHARE covered eleven European countries and Israel. Our recoding exercise only uses the Dutch sample of this wave because CASCOT is currently available in two languages English and Dutch - and the English language is not present in SHARE data.

We recoded job descriptions using CASCOT-NL in its semiautomatic mode by setting a minimum score of 70 and with the assistance of an expert coder who was a Dutch native speaker and who has been involved in occupational coding and occupational databases for many years. As mentioned above, in all cases in which CASCOT-NL attributed a score greater than 70, it coded the text automatically. The expert coder manually coded all the residual cases. Consistent with what is done in SHARE, the operator coded vague responses by means of trailing zeros. The manual recoding was done twice: with and without ancillary information. The use of ancillary variables increased the comparability between the SHARE and CASCOT-NL coding. Moreover, the operator made use of the same ancillary variables (on training and qualifications needed for the job and on the industry the respondent was working in) used by SHARE coders. In order to avoid the 'anchoring effect' - that is, the tendency of human coders to select the code already in front of them (see Cheeseman Day 2014) - the expert coder used a recent CBS coding index (see http://www.cbs.nl/nl-NL/menu/methoden/classificaties/overzicht/sbc/default. $\mathrm{htm}$ ) including 4,705 job titles rather than the list of codes recommended by the CASCOTNL classification file ISCO v1.1. We believe that the combination of a high-quality software program (which automatically coded a high proportion of cases at the four-digit level, see below), an expert coder, the use of ancillary information, and the use of an extensive external job titles list ensured a high level of coding and provided better coding than manual SHARE coding. In the following, we will therefore consider the CASCOTNL coding (the version exploiting ancillary variables) as our benchmark.

Tables $1 \mathrm{a}$ and $1 \mathrm{~b}$ show the number of recoded cases available for our statistical analysis: 2,790 observations, of which 1,773 concern last job (Table 1a) and 1,017 current job (Table 1b). The higher frequency for last job in comparison with current job primarily reflects the distribution of respondents by work status in the first wave of SHARE. Two points are worth mentioning with respect to Tables $1 \mathrm{a}$ and $1 \mathrm{~b}$ : first, the number of cases automatically coded (scoring above 70 ) at four-digit level is high (40\%, i.e., 708 out of the 1,773 total observations for last job; $55 \%$, i.e., 557 out of the 1,017 observations for 
Table 1a. Output of CASCOT-NL recoding at different number of digits by score level and use of ancillary variables - Last job: frequencies, and row percentages (in italics).

\begin{tabular}{|c|c|c|c|c|c|c|}
\hline & & 4 digit & 3 digit & 2 digit & 1 digit & Total \\
\hline Score above $70^{*}$ & & 708 & 108 & 142 & 71 & 1029 \\
\hline \multirow[t]{4}{*}{ Score below $70 * *$} & No ancillary & 336 & 146 & 115 & 73 & 670 \\
\hline & & 50 & 22 & 17 & 11 & 100 \\
\hline & With ancillary & 596 & 98 & 23 & 27 & 744 \\
\hline & & 80 & 13 & 3 & 4 & 100 \\
\hline \multicolumn{2}{|l|}{ Total } & & & & & 1,773 \\
\hline
\end{tabular}

*automatically coded; **manually coded.

current job); second, making use of ancillary information dramatically increases the number of digits at which the observations are coded. For example, for last job, the percentage of cases coded at four-digit level among those which scored below 70 increased from 50 to $80 \%$ when using ancillary variables.

The main issue arising when comparing codes from SHARE and CASCOT-NL is the lack of homogeneity in the classification structure. SHARE Netherlands coded job descriptions at three-digit ISCO-88 level (note that all other countries coded jobs at ISCO88 four-digit level, see above), while CASCOT-NL, as described above, coded to ISCO-08 four-digit level. We therefore homogenised the two sets of codes as follows. First, we converted CASCOT-NL codes from ISCO-08 into ISCO-88 using an official correspondence table (ILO 2014). Unfortunately, according to this table, there is a 'many-toone' correspondence between ISCO-88 and ISCO-08, that is, multiple ISCO-88 codes are associated with the same four-digit ISCO-08 code. In our data, this occurs for about $20 \%$ of the sample. In these cases, we associated multiple ISCO-88 codes with the same job description. Considering the issue of nonunivocal correspondence between different versions of ISCO, we decided that a job description would have a different code if the ISCO- 88 code attributed by SHARE coders is not equal to any of the ISCO- 88 codes resulting from the conversion of the CASCOT-NL output into ISCO-88. Otherwise, the

Table 1b. Output of CASCOT-NL recoding at different number of digits by score level and use of ancillary variables - Current job: frequencies, and row percentages (in italics).

\begin{tabular}{lrrrrrr}
\hline & 4 digit & 3 digit & 2 digit & 1 digit & Total \\
\hline Score above 70* & & 557 & 87 & 0 & 7 & 651 \\
& & 86 & 13 & 0 & 1 & 100 \\
\hline Score below 70** & No ancillary & 188 & 104 & 37 & 37 & 366 \\
& & 51 & 28 & 10 & 10 & 100 \\
& With ancillary & 241 & 53 & 42 & 30 & 366 \\
& & 66 & 14 & 11 & 8 & 100 \\
\hline Total & & & & & $\mathbf{1 , 0 1 7}$ \\
\hline
\end{tabular}

*automatically coded; **manually coded. 
job description has the same code. Second, we only considered three digits. In summary, we compared codes from SHARE and CASCOT-NL in terms of three-digit ISCO-88 codes.

\section{Results}

\subsection{Descriptive Statistics}

Figures $1 \mathrm{a}$ and $1 \mathrm{~b}$ show the distribution of occupations by ISCO-88 Major groups according to both SHARE and CASCOT-NL coding, and for last and current job respectively. Given the fact that multiple codes are sometimes associated with the same individual in our recoding exercise due to the lack of one-to-one correspondence between ISCO-08 and ISCO-88, we used weighting to construct these figures. In particular, when $n$ codes are associated with the same individual, we attributed a weight equal to $1 / n$ to each of them.

The figures reveal sizable differences between ISCO distributions of current and last job. The share of professionals and associate professionals (ISCO Major groups 2 and 3) is much higher for current job than for last job, whereas the opposite occurs for lower-skilled occupations. This fact may reflect changes in occupational structure over time, possibly due to technological change or international trade, as last job may often refer to occupations started early in an individual's working career. There is in fact extensive literature showing that technological progress and increased competition from low-wage countries have changed labour demand in favour of more skilled occupations (e.g., Autor et al. 2003; Feenstra and Hanson 1996). In addition, these differences in the distribution of occupations may also be due to selective retirement: manual workers may retire earlier from the labour force than nonmanual workers and therefore may be overrepresented in

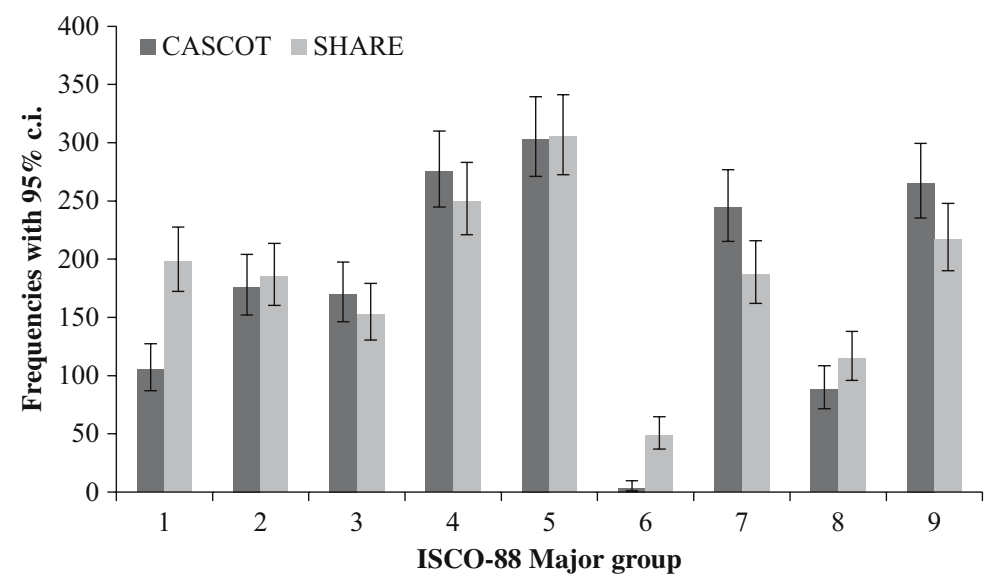

Fig. 1a. Distribution of occupation by ISCO-88 Major group, CASCOT-NL and SHARE coding - Last job (frequencies with $95 \%$ confidence intervals). Legend: $1=$ Legislators, senior officials and managers, $2=$ Professionals, $3=$ Technicians and associate professionals, $4=$ Clerks, $5=$ Service workers and shop and market sales workers, $6=$ Skilled agricultural and fishery workers, $7=$ Craft and related trades workers, $8=$ Plant and machine operators and assemblers, $9=$ Elementary occupations. 


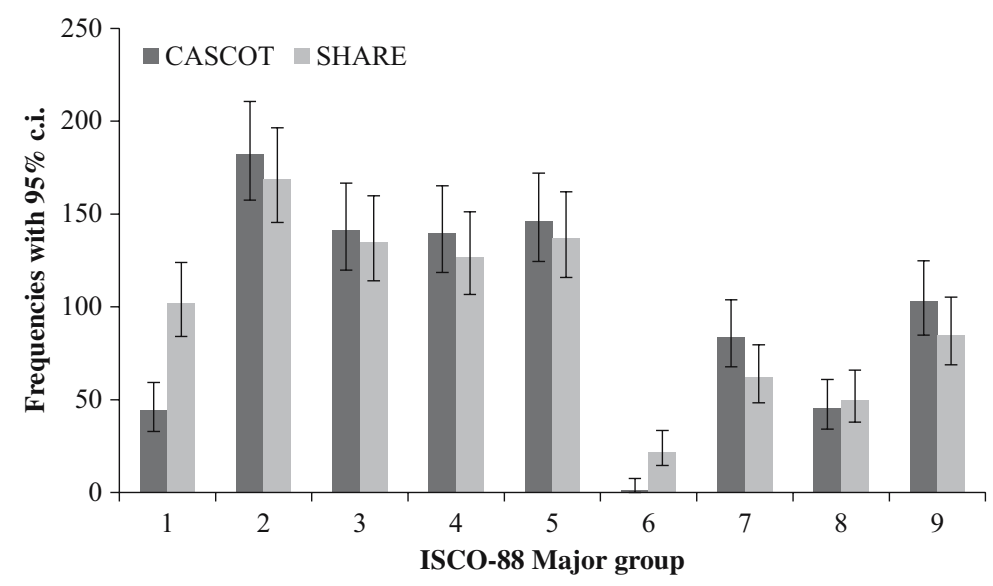

Fig. 1b. Distribution of occupation by ISCO-88 Major group, CASCOT-NL and SHARE coding - Current job (frequencies with 95\% confidence intervals). Legend: $1=$ Legislators, senior officials and managers, $2=$ Professionals, $3=$ Technicians and associate professionals, $4=$ Clerks, $5=$ Service workers and shop and market sales workers, $6=$ Skilled agricultural and fishery workers, $7=C r a f t$ and related trades workers, $8=$ Plant and machine operators and assemblers, $9=$ Elementary occupations.

the last job variable. The contrary may occur for professionals, who may remain in the labour market even beyond the standard retirement age. The issue of selective retirement is non-negligible in countries favouring part-time work such as the Netherlands. Finally, note that the number of observations for each Major group is limited; consequently, statistical analyses disaggregated by ISCO groups at $2 / 3$ digits are not presented in this section.

Tables $2 \mathrm{a}$ and $2 \mathrm{~b}$ report frequency and percentage of same and different codes for last and current job respectively. The percentage coded differently (which we call 'disagreement rate' hereafter) appears high even when the comparison is made at the one-digit level (28\% for last job and $29 \%$ for current job). As expected, such percentages rise with the number of digits at which the comparison is performed. This result is in line with the meta-analysis of the results from occupational recoding studies carried out by Elias (1997) and cited in the introduction. The disagreement rate is slightly higher for current job than for last job: for example, at three-digit level, $47 \%$ of texts for current job are coded differently, compared with $43 \%$ for last job. A possible explanation for this last finding is related to sample composition: we have seen that the ISCO-88 Major group distribution for current and last job are different for good reasons (Figure 1), and some

Table 2a. Observations coded equally and differently by CASCOT-NL and SHARE at different number of digits - Last job (frequencies and percentages).

\begin{tabular}{lrrrrrrrr}
\hline & \multicolumn{2}{c}{1 digit } & & \multicolumn{2}{c}{2 digit } & & \multicolumn{2}{c}{3 digit } \\
\cline { 2 - 3 } ISCO-88 Code: & Freq. & Percent & & Freq. & Percent & & Freq. & Percent \\
\hline Same & 1,195 & 72 & & 1,086 & 65 & & 937 & 56 \\
Different & 464 & 28 & & 573 & 35 & & 722 & 44 \\
Total & 1,659 & 100 & & 1,659 & 100 & & 1,659 & 100 \\
\hline
\end{tabular}


Table $2 b . \quad$ Observations coded equally and differently by CASCOT-NL and SHARE at different number of digits - Current job (frequencies and percentages).

\begin{tabular}{|c|c|c|c|c|c|c|}
\hline \multirow[b]{2}{*}{ ISCO-88 Code: } & \multicolumn{2}{|c|}{1 digit } & \multicolumn{2}{|c|}{2 digit } & \multicolumn{2}{|c|}{3 digit } \\
\hline & Freq. & Percent & Freq. & Percent & Freq. & Percent \\
\hline Same & 631 & 71 & 555 & 62 & 465 & 52 \\
\hline Different & 258 & 29 & 334 & 38 & 424 & 48 \\
\hline Total & 889 & 100 & 889 & 100 & 889 & 100 \\
\hline
\end{tabular}

ISCO groups may be more subject to coding errors than others (see Table 3). Finally, this finding is consistent with the explanation proposed by Ellison (2014) and mentioned earlier in this article: individuals tend to give too many details about their current job because they think it is complex, while this occurs to a lesser extent for last job.

Table 3 reports disagreement rates for ISCO-88 Major groups, for both last and current job. There is wide variety in the disagreement rate across groups, with groups 1 ("Legislators, senior officials and managers") and 3 ("Technicians and associate professionals") being those with the highest values. The percentage of observations coded differently is also high for the current job variable in group 6 ("Skilled agricultural and fishery workers"). Agricultural workers are known to be difficult to code and some occupations in this category were subject to changes in classification from ISCO-88 to ISCO-08. The high disagreement rate for this category may be due to the fact that the ISCO-88 Unit groups of 1221, "Production and operations department managers in agriculture forestry and fishing", and 1311, "General managers in agriculture, forestry and fishing", were removed from Major group 1 in the ISCO-08 classification. The occupations included within this category were moved to Sub-Major Group 61 and merged with the relevant supervisory groups (UN 2007). Therefore, "General managers in agriculture, hunting, forestry and fishing" were classified as ISCO-88 Unit group 1311, and should not be included within Major group 6.

In addition to disagreement rates, in the following we attempt to quantify the degree of disagreement between the two sets of codes in terms of skill levels (where a hierarchical order and a measure of difference - or 'distance' - among groups in terms of skills can be established). The ILO in fact maps ISCO Major groups into skill levels (Elias 1997; ILO 2012) which can then be mapped onto education levels defined by ISCED-97 (see Table A1 in the Appendix). For example, the difference in skill level between a job in ISCO-88 Major group 9 (Elementary Occupations, skill level 1) and 2 (Professionals, skill level 4) is equal to 3. We first performed the Wilcoxon signed-rank test for paired data (Wilcoxon 1945). The results of this test were very different for last and current job. While for last job the null hypothesis that SHARE and CASCOT-NL coding distributions will be the same was not rejected ( $p$-value $=0.12$ ), for current job this hypothesis was rejected even at one percent significance level $(p$-value $=0.0004)$. Tables $4 \mathrm{a}$ and $4 \mathrm{~b}$ present the bivariate distributions - SHARE vs CASCOT-NL skill-level groups - for last and current job respectively. The tables show that most of the coding disagreement occurs within similar groups of occupations. Looking at last job, $85 \%$ of occupations coded into skill group 1 in SHARE are coded into the same skill group in CASCOT-NL. The percentages of correct 


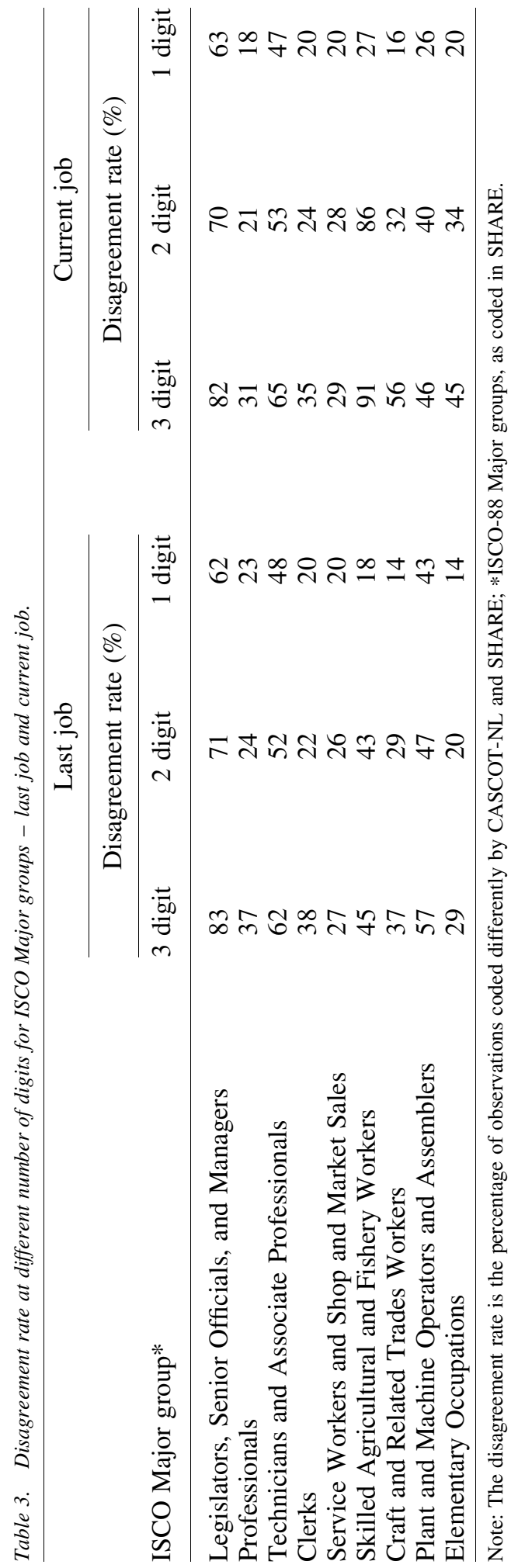


Table 4a. Skill levels bivariate distributions - SHARE vs CASCOT-NL - Last job (\%).

\begin{tabular}{lrrrrr}
\hline CASCOT $\rightarrow$ & & 3 & 4 & Total \\
SHARE $\downarrow$ & 1 & 2 & 1 & 0 & 100 \\
\hline 1 & $\mathbf{8 5}$ & 14 & 10 & 1 & 100 \\
2 & 6 & $\mathbf{8 3}$ & $\mathbf{5 2}$ & 17 & 100 \\
3 & 3 & 28 & 19 & $\mathbf{7 2}$ & 100 \\
4 & 0 & 9 & 17 & 11 & 100 \\
Total & 16 & 56 & &
\end{tabular}

coding are around $83 \%$ for skill group 2, 52\% for skill group 3 and $72 \%$ for skill group 4 . As suggested by the Wilcoxon signed-rank test, these percentages are lower when considering current job, with the exception of skill level 4 . We currently have no explanation for the latter.

In the remainder of the article, we investigate which individual characteristics are more likely to be associated with coding disagreement. To this end, we performed both univariate and multivariate analyses. The tables reporting univariate statistics can be found in the Appendix. In particular, Table A2 presents the disagreement rate according to education level, Table A3 according to gender and Tables A4a and A4b according to industry for last and current job respectively. The figures clearly show that the rates of coding disagreement differ substantially across education and gender, with higher rates for more educated individuals (only for last job) and for males. No clear patterns emerge from the tables on disagreement rates for industry, probably because of the very low number of observations in some groups. In the following subsection, we explore these results in more detail based on a multivariate analysis.

\subsection{Multivariate Analysis: Predicting Coding Errors}

In this section, we estimate a set of Linear Probability Models (LPM) that can be used to predict coding errors. They can also provide information about which ISCO groups are more difficult to code. An LPM is a multiple linear regression model with a binary dependent variable (Wooldridge 2010). As a robustness check, we also estimated the same equations using nonlinear methods and the results were almost the same. The dependent variable in these models allows for the possibility of multiple correspondences in the ISCO-08 to ISCO-88 conversion tables. In other words, in our models the dependent variable is a dummy variable equal to 1 if the three-digit ISCO- 88 code provided by SHARE is not equal to any of the three-digit ISCO- 88 codes resulting from the conversion of the ISCO-08 CASCOT-NL code into ISCO-88; otherwise, the dependent variable is equal to 0 . We estimated weighted regressions to account for the multiple correspondences in the ISCO-08 to ISCO-88 conversion tables (where each observation is given a weight that is inversely related to the number of correspondences). The results for the unweighted regressions were virtually unchanged. Moreover, we considered two alternative dependent variables, namely a dummy for being coded differently at one- or two-digit ISCO level. Again, the results of these regressions were similar to those reported in the paper. All these additional results are available from the authors upon request. 
Table 4b. Skill levels bivariate distributions - SHARE vs CASCOT-NL - Current job (\%).

\begin{tabular}{|c|c|c|c|c|c|}
\hline $\begin{array}{l}\text { CASCOT } \rightarrow \\
\text { SHARE } \downarrow\end{array}$ & 1 & 2 & 3 & 4 & Total \\
\hline 1 & 80 & 16 & 2 & 2 & 100 \\
\hline 2 & 4 & 82 & 13 & 1 & 100 \\
\hline 3 & 4 & 18 & 50 & 28 & 100 \\
\hline 4 & 1 & 8 & 14 & 77 & 100 \\
\hline Total & 12 & 47 & 21 & 21 & 100 \\
\hline
\end{tabular}

The set of LPM we estimated differ in terms of the set of explanatory variables. We estimated separate models for last and current job. By pooling these two variables, we would have considerably increased the number of observations and perhaps improved the precision of our estimates. However, the descriptive findings outlined earlier suggest that coding disagreements for current and last job have different patterns: our econometric results (see below) clearly confirm that pooling current and last job - assuming that explanatory variables have the same effect on the probability of miscoding for current and last job - would have led to misspecification.

Table 5a reports LPM estimates for the probability of the last job being miscoded at three-digit level. We present six specifications in this table. The first three columns include only individual and job-related characteristics, that is, they do not include any variable that results from the coding process. Models 1-3 can be used during (or before) 'office' coding: if the survey containing the questions on occupation also provides information on the explanatory variables included in the estimated equation, their values can be 'plugged in' and used to predict the likelihood that any attributed code is correct or incorrect.

Specification 1 includes basic individual characteristics present in almost all surveys as explanatory variables, namely gender, educational attainment (four aggregated ISCED-97 groups), whether the individual is self-employed (controlling for self-employment is also important to identify the gender effects, as females are overrepresented within this group of workers), and whether the individual is foreign born. Our results indicate that females are $29 \%$ less likely to be miscoded than males. Remarkably, there is a strong positive gradient between education and coding disagreement: relative to individuals with no or primary education, those with an upper and postsecondary degree (ISCED 3-4) have a $14 \%$ higher probability of being miscoded; this percentage rises to about $18 \%$ for individuals holding a tertiary education degree (ISCED 5-6). Being self-employed translates into about ten percent higher chance of being miscoded. The same holds for being born abroad. With the exception of the dummy variable of ISCED 2, all of the explanatory variables included in this model were significant at least at five percent level. This very basic model with few right-hand side variables is able to explain about twelve percent of the variability in the dependent variable (see the R-squared statistic at the bottom of the table).

Specification 2 includes two additional regressors: age and a cognitive skills index. These individual characteristics (especially the latter) might be particularly important for predicting miscoding when looking at mature $(50+)$ individuals. It might be expected that older individuals and individuals with less cognitive functioning provide poorer job 


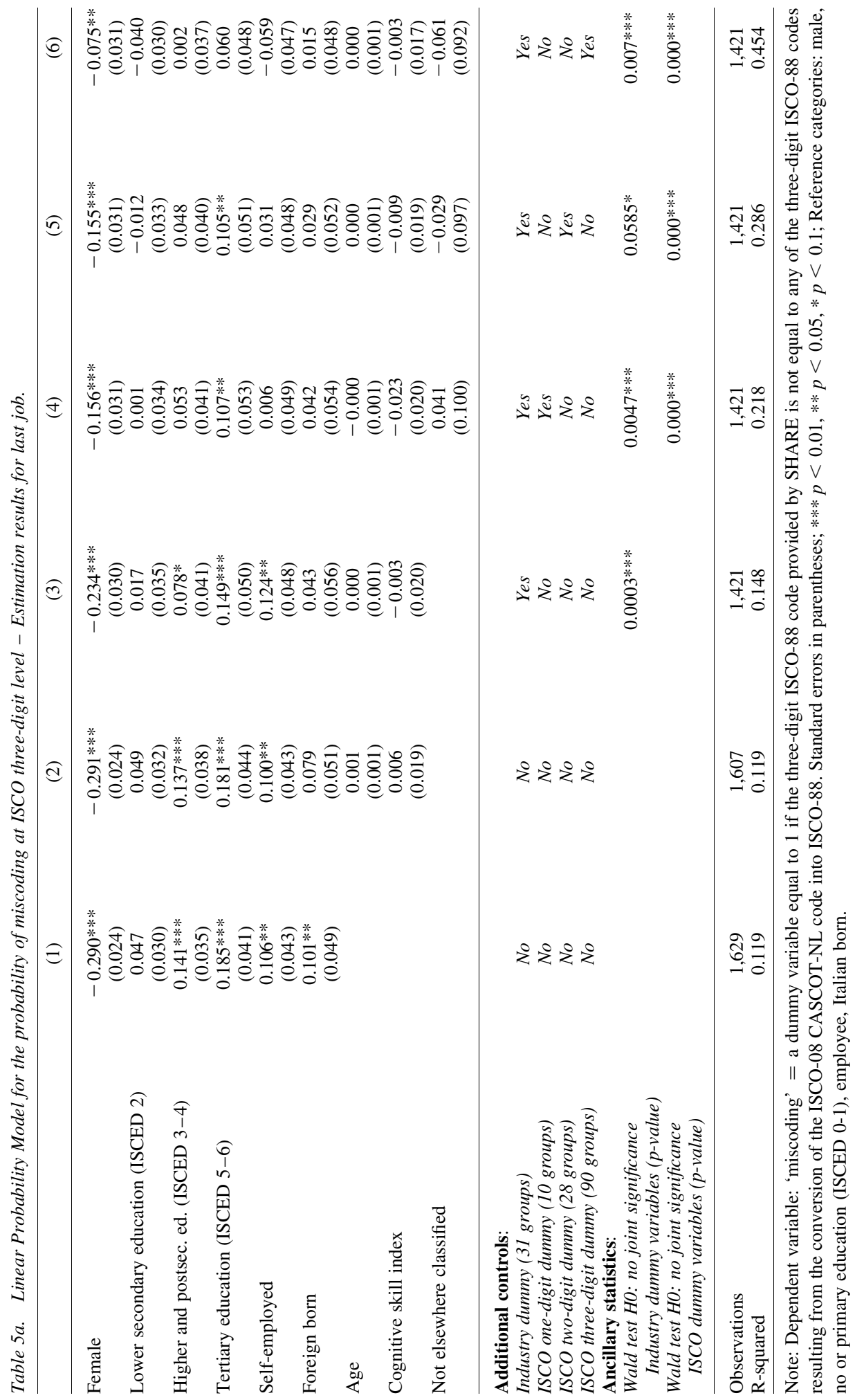


descriptions, which are thus more difficult to code. A 'Cognitive Functioning' module included in SHARE reports the results of simple tests of verbal fluency, such as counting the number of items that can be named in one minute; recalling as many words as possible from a ten-word list; and testing daily life numerical calculations (see e.g., Christelis et al. 2010). Based on these tests, we built an index of cognitive abilities (Leist et al. 2013). This index is given by the average value of the standardised results of these tests. The higher the value of the index, the higher the cognitive abilities. We did not find any significant effect of these two variables on the probability of miscoding last job.

In Specification 3, we additionally controlled for industry by including a set of 31 industry dummy variables in the model. Industry was classified using NACE Codes, Version 4 Rev. 11993 (see http://www.top500.de/nace4-e.htm for a description of NACE Version 4 Rev. 1 and MEA 2013, 32-33 for the shorter classification used in SHARE). They jointly affect the probability of coding error, as indicated by the result of the Wald test reported at the bottom of the table $(p$-value $=0.0003)$. Remarkably, even after controlling for industry, the effects of gender, educational attainment, and being selfemployed on coding disagreement remained significant, although they were somewhat attenuated. This richer specification is able to explain about $15 \%$ of the observed miscoding.

Specifications 4 to 6 add a set of variables to individual and job-related characteristics that result from coding the verbatim response to the open-ended questions on occupation. Specification 4 includes ten ISCO one-digit (Major) groups fixed effects, Specification 5 includes 28 ISCO 2-digits (Sub-major) groups fixed effects, and Specification 6 includes 90 ISCO three-digit (Minor) groups fixed effects. Moreover, all models include a dummy variable for being coded as "Not elsewhere classified" (NEC). This was constructed by looking at the ISCO-88 four-digit codes, as coded by CASCOT-NL software. This NEC dummy was equal to 1 if the ISCO-88 fourth digit was equal to 9 , which, according to ILO's guidelines, refers to occupational categories that are not classified into other specific categories within the classification. This variable includes ISCO categories which usually contain many types of clerical jobs. We thus expect NEC jobs to be more likely to be miscoded.

These extended specifications can be used to predict coding errors during CAPI interviews. In addition to proposing a given ISCO code, the coding software (such as the 'Jobcoder', see Section 2) would be able to evaluate the quality of the proposal by determining the probability that it is correct (similarly to the score produced by CASCOT). If this probability is low, the interviewee can be asked for additional information. Another possible use of the predictive equations 4 to 6 is to 'double check' office coding. After an ISCO code has been attributed to the occupation, all of the explanatory variables are in fact available for error prediction.

These specifications - especially Specification 6 - are very demanding in terms of data requirements, and we expect to have limited variability in individual and job-related characteristics once we condition on being coded in a given ISCO group. Nonetheless, the negative coefficient for "female" remained significant at five percent even after controlling for ISCO Minor groups. The same occurred for the industry dummy variables (the $p$-value of the Wald test for no joint significance of the industry dummy variables is almost equal 
to 0 in Specification 6). This independent source of variation increases the overall explanatory power of our error-predicting equations.

Adding ISCO dummy variables to the model dramatically improves the model fit: the R-squared in fact increases from 15\% (Specification 3; no information on ISCO codes) to $22 \%$ (Specification 4) and progressively increases further with the number of ISCO digits, up to about $45 \%$ (Specification 6). The $p$-value of the Wald test for no joint significance of the ISCO group dummy variables is always equal to 0 .

As outlined at the beginning of this section, the estimated equations can also provide information about which ISCO groups are more likely to be miscoded. Figures 2 and 3 present the predictions of models 4 and 5 respectively for last job. Figure 2 shows that ISCO Major groups 1, 3, and 8 are the most miscoded groups. Prediction uncertainty is limited at ISCO one-digit level, with the exception of group 6. These predictions can be compared with the disagreement rates reported in Table 3. In some cases, remarkable differences emerge. For example, the disagreement rate of ISCO Major group 9 ("Elementary occupations") is equal to $29 \%$ in Table 3, whereas it is much higher (the point estimate being around 40\%) in Figure 2. This difference is due to composition effects - mainly related to industry - which are accounted for in Equation (4). Figure 3 highlights that ISCO groups 11 ("Legislators and senior officials"), 12 ("Corporate managers"), 33 ("Teaching associate professionals"), 82 ("Machine operators and assemblers") and - with higher uncertainly - groups 62 ("Subsistence agricultural and fishery workers") and 81 ("Stationary-plant and related operators") are the ISCO Submajor groups most subject to coding error. We do not present predictions for ISCO Minor groups from Specification 6 since they were too imprecise to be reliable out of sample.

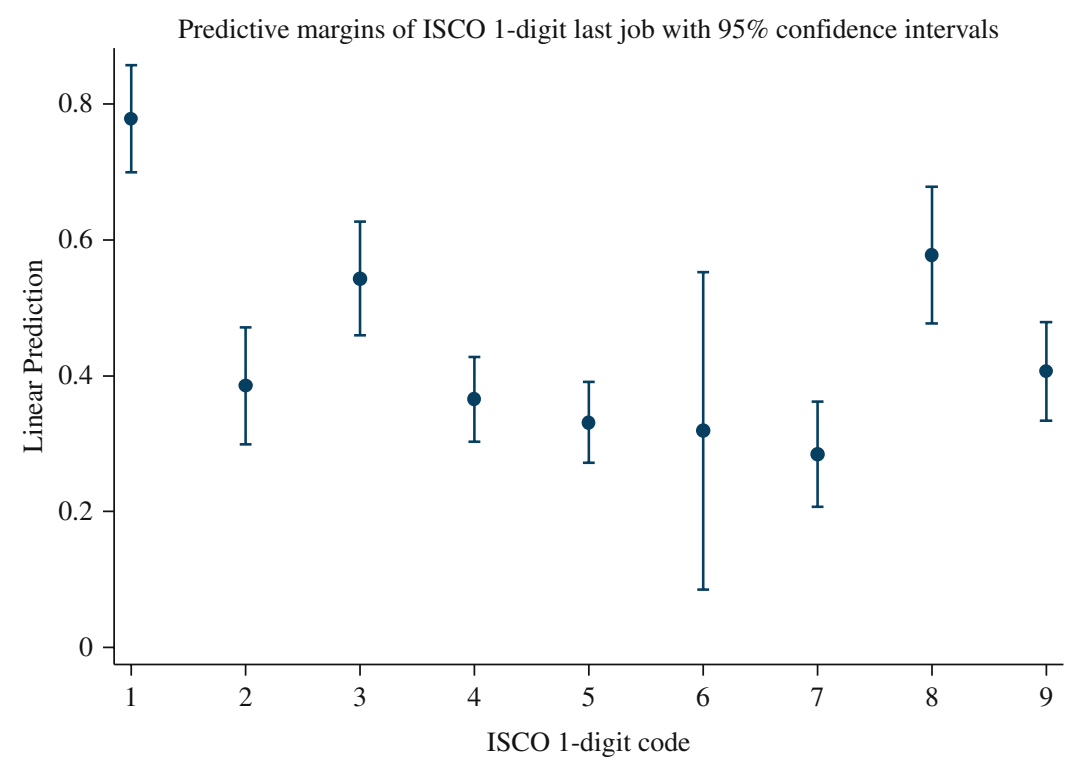

Fig. 2. Predicted probability of coding error with 95\% confidence intervals for ISCO one-digit level - Last job. Legend: $1=$ Legislators, senior officials and managers, $2=$ Professionals, $3=$ Technicians and associate professional, $4=$ Clerks, $5=$ Service workers and shop and market sales workers, $6=$ Skilled agricultural and fishery workers, $7=$ Craft and related trades workers, $8=$ Plant and machine operators and assemblers, $9=$ Elementary occupations. Note: Predictions from Specification 4, Table 5 a. 


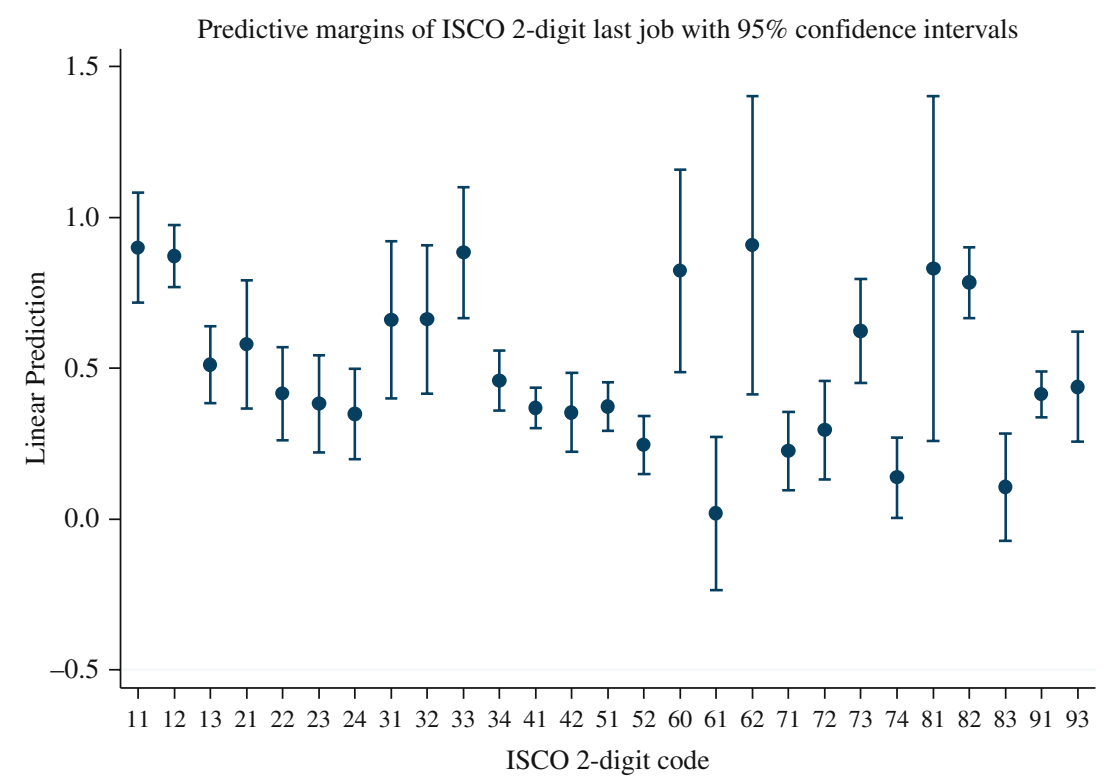

Fig. 3. Predicted probability of coding error with 95\% confidence intervals for ISCO two-digit level - Last job. Note: Predictions from Specification 5, Table 5 .

Table 5 b reports LPM estimates for the probability of the current job being miscoded at ISCO three-digit level. To facilitate comparability, we report the same six specifications presented in Table 5a. The results for current job are very different from those obtained for last job. First, there is no education miscoding gradient for the current job variable. Second, the cognitive skills index has a sizable and significant effect on miscoding, even when ISCO Minor group is controlled for. According to Specification 6, one standard deviation (0.67) increase in this variable (corresponding roughly to a change from its sample median to its $90^{\text {th }}$ percentile) determines a reduction in the probability of miscoding equivalent to $5.7 \%(=-0.086 * 0.67)$. Counterintuitively, age has a negative sign, but its effect is quantitatively very small and disappears once the ISCO two-digit level is included in the model (Specification 5). Gender, industry and ISCO groups maintain their strong explanatory power (see the results of corresponding Wald tests at the bottom of the table for the last two groups of variables).

Figures 4 and 5 present coding error predictions for current job using model specifications 4 and 5 respectively. Figure 4 highlights that ISCO Major groups 1, 3, and 6 are the most miscoded groups. The most relevant difference with respect to last job concerns Major group 6: although not precisely estimated, the point estimate of the predicted error is about $90 \%$ for current job (it is about $30 \%$ for last job; this difference is statistically significant at five percent level). We provided an explanation for the high value of group 6 miscoding for current job in the previous section. Error prediction for group 8 is much higher for last job (point estimate, 0.58) than for current job (0.35). Figure 5 shows that the predicted probabilities of coding error for current job are much higher than for last job for the following ISCO Sub-major groups: 34 ("Other associate professionals"), 61 ("Market-oriented skilled agricultural 


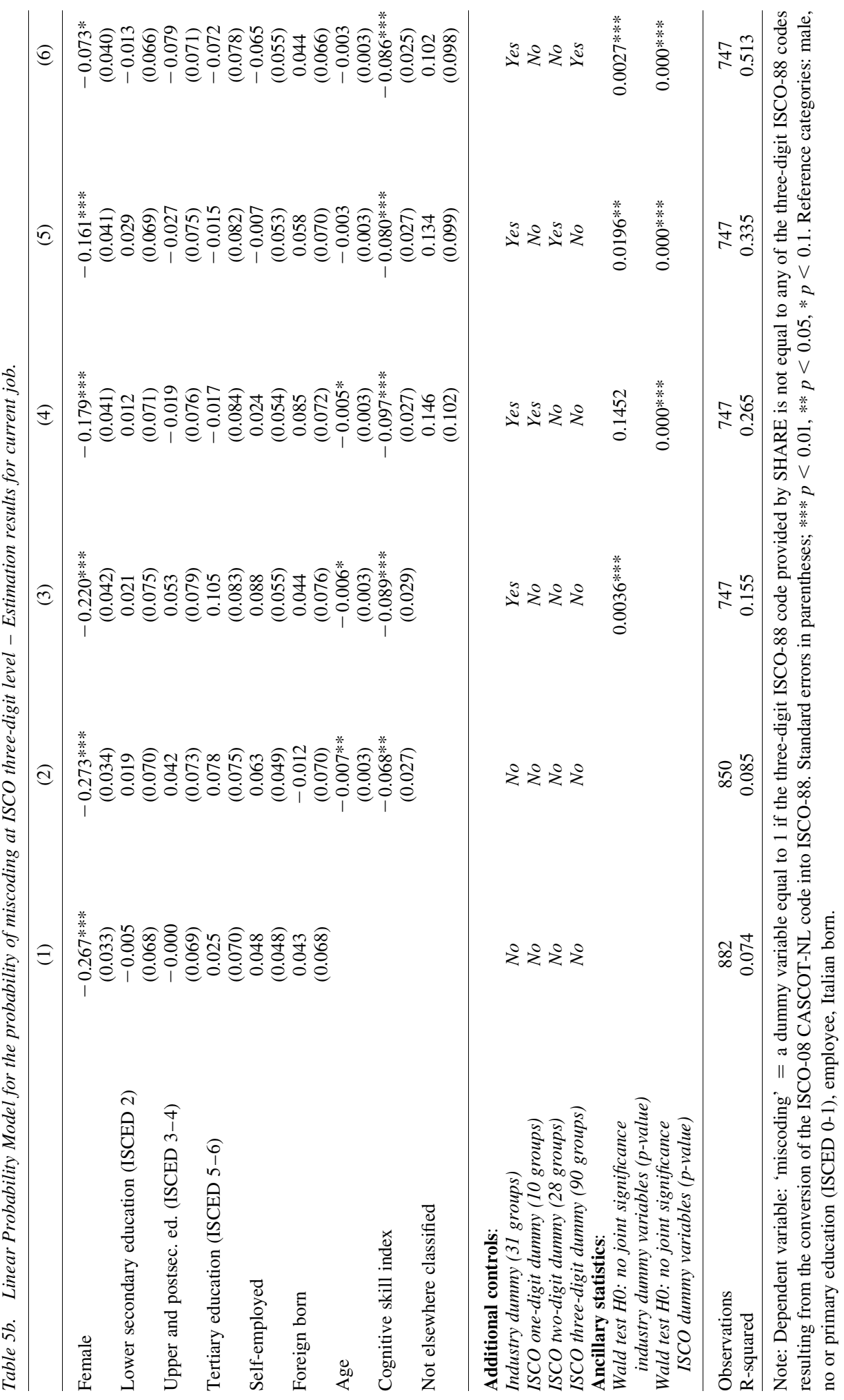


Predictive margins of ISCO 1-digit current job with 95\% confidence intervals

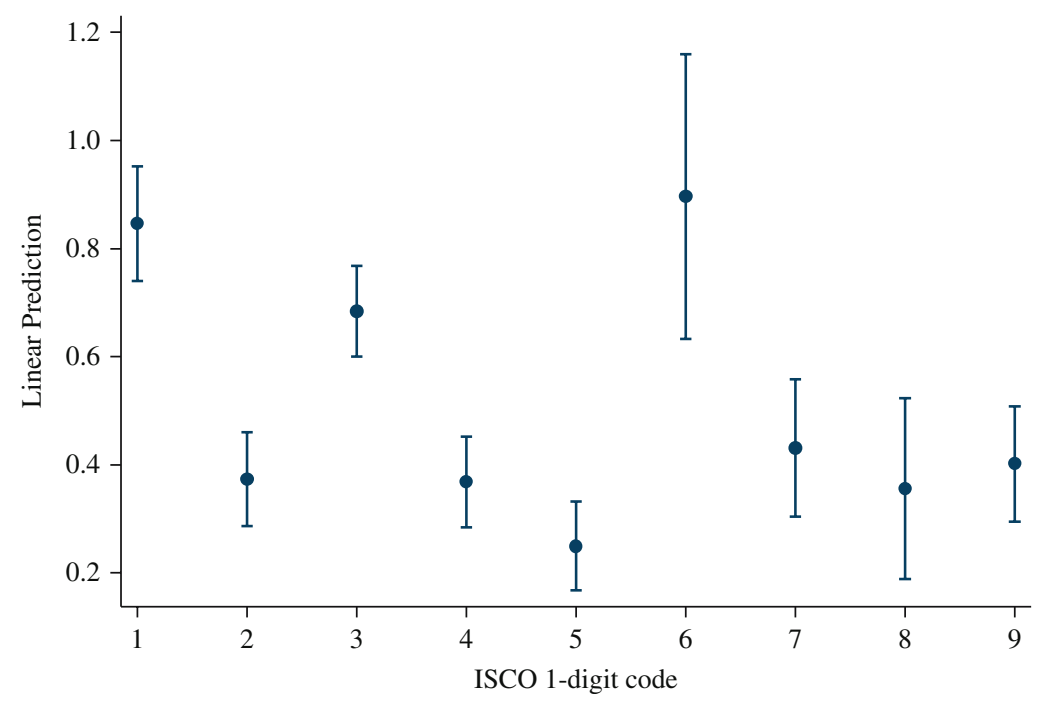

Fig. 4. Predicted probability of coding error with 95\% confidence intervals for ISCO one-digit level - Current job. Legend: $1=$ Legislators, senior officials and managers, $2=$ Professionals, $3=$ Technicians and associate professionals, $4=$ Clerks, $5=$ Service workers and shop and market sales workers, $6=$ Skilled agricultural and fishery workers, $7=$ craft and related trades workers, $8=$ plant and machine operators and assemblers, $9=$ elementary occupations. Note: Predictions from Specification 4, Table $5 b$.

and fishery workers"), 71 ("Extraction and building trades workers"), and 74 ("Other craft and related trades workers"). In contrast, and for good reasons, they are lower for ISCO groups 32 ("Life science and health associate professionals"), 42 ("Customer services clerks"), 52 ("Models, salespersons and demonstrators"), and 83 ("Drivers and

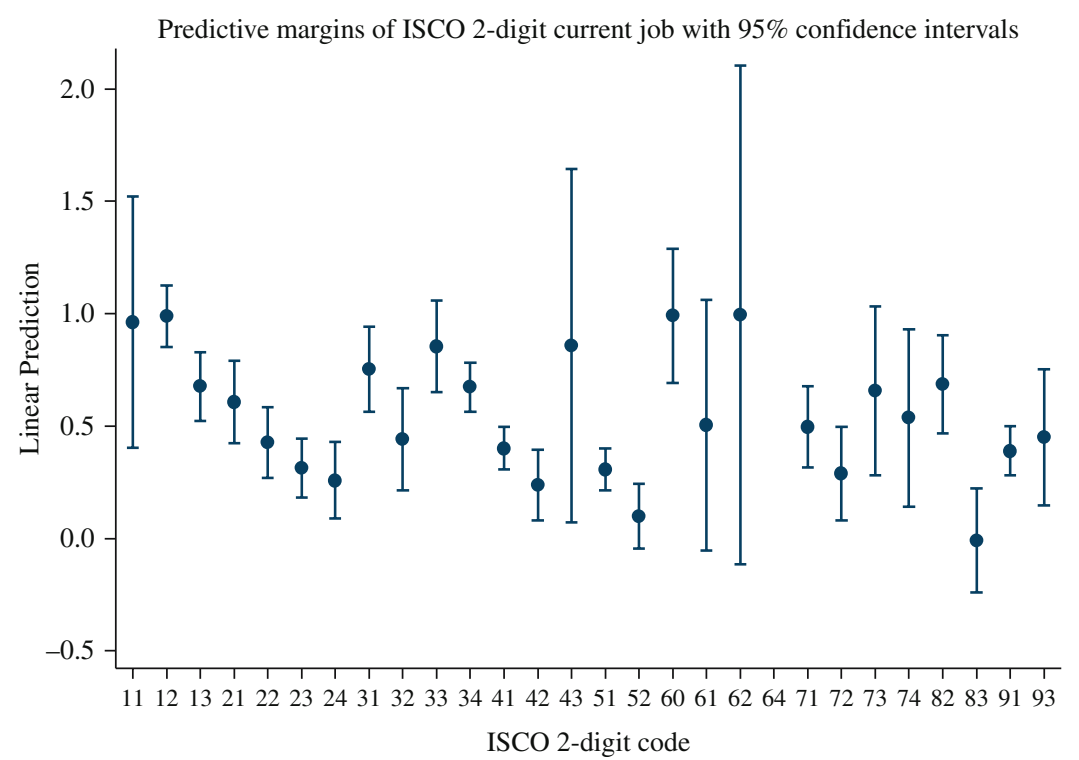

Fig. 5. Predicted probability of coding error with $95 \%$ confidence intervals for ISCO two-digit level - Current job. Note: Predictions from Specification 5, Table 5 b. 
mobile-plant operators"). Most of these differences are, however, not statistically significant.

\section{Discussion and Conclusions}

There is growing use of information on occupation in research in the fields of labour economics and sociology, but the quality of occupational data, which is of key importance, is often neglected. Most occupational information in survey data is obtained from direct questions addressed to respondents who provide answers in an open text field. This allows the classification of occupations at a detailed level of disaggregation, but requires coding afterwards ('office coding'). Promising attempts to code occupational data during CAPI interviews are currently being made using a look-up table or coding index, such as the semantic text-string matching algorithm used in SHARE Wave 6.

In this study, we recoded open-ended questions on occupation for last and current job in the Dutch sample of SHARE data using CASCOT, a well-known and high-quality software program for automatic ex-post coding. We used a Dutch version of CASCOT (CASCOT-NL) in its semiautomatic mode. The combination of a high-quality software program, an expert coder, the use of ancillary information, and the use of an extensive external job titles list ensured a high level of accuracy in coding. A key novelty of our article is the provision of equations that can predict coding errors. We estimated two sets of equations. The first included only individual and job-related characteristics. These equations can be used during (or before) 'office' coding: if the survey containing the questions on occupation also provides information on the explanatory variables included in the estimated equation, their values can be used to predict the likelihood that any code attributed is (in)correct. The second set of equations also includes ISCO codes and can be used to predict coding errors during the CAPI interview. In addition to proposing a given ISCO code, the coding software can use these equations to determine the probability that the code is correct. If this probability is low, the interviewee can be asked for additional information. Another possible use of the second set of equations is to recheck office coding: after an ISCO code has been attributed to the occupation, all of the explanatory variables are in fact available for error prediction.

The main findings of this study were: first, the incidence of miscoding in SHARE is high even when comparison is performed at one-digit level - at $28 \%$ for last job and $30 \%$ for current job. Second, the use of ancillary information drastically increases the number of digits at which the observations are coded. Third, coding errors in occupation are more pronounced for males than for females. Fourth, for the last job variable, they are more likely for more educated individuals and for the self-employed. Fifth, cognitive abilities seem to play an important role in explaining coding errors for current job. Sixth, predictive error equations have a high explanatory power and, finally, ISCO groups 1, 3, and 6 for current job, and 8 for last job, are more susceptible to miscoding.

To reduce coding errors after the interview ('office coding') we suggest a semiautomatic software program be used, which also exploits the information provided by ancillary variables as much as possible, such as training and qualifications needed for the job and the industry in which the respondent is working. Many multidisciplinary surveys targeted at older individuals collect information on their last and current jobs (e.g., SHARE, the 
English Longitudinal Study of Ageing, and the US Health and Retirement Study). When coding occupations in these surveys, one should ideally make use of measures of individuals' cognitive ability to assist in determining the likelihood of the attributed code being correct. Additional specific questions targeted at the abovementioned groups of occupations should be included in the questionnaire. The main advantage of coding during the interview is that if the response is vague or imprecise, the interviewer can ask the respondent for a more precise job description. Predictive error equations such as those presented in this study may complement the coding software in this novel context.

\section{Appendix}

Table A1. Mapping of ISCO-08 Major groups to skill levels (Cols. 1 and 2) and mapping of the four ISCO-08 skill levels to ISCED-97 levels of education (Cols. 2 and 3).

\begin{tabular}{lcc}
\hline ISCO-08 Major groups & Skill level & ISCED-97 level \\
\hline 1. Managers & $3+4$ & $5 \mathrm{~b}+6,5 \mathrm{a}$ \\
2. Professionals & 4 & $6,5 \mathrm{a}$ \\
3. Technicians and associate professionals & 3 & $5 \mathrm{~b}$ \\
4. Clerical support workers & 2 & $4,3,2$ \\
5. Services and sales workers & 2 & $4,3,2$ \\
6. Skilled agricultural, forestry and fishery workers & 2 & $4,3,2$ \\
7. Craft and related trades workers & 2 & $4,3,2$ \\
8. Plant and machinery operators and assemblers & 2 & $4,3,2$ \\
9. Elementary occupations & 1 & 1 \\
\hline
\end{tabular}

Note: ISCED-97 levels of education: Level 1 = Primary education or first stage of basic education; Level $2=$ Lower secondary or second stage of basic education; Level $3=$ (Upper) secondary education; Level $4=$ Postsecondary nontertiary education; Level $5 \mathrm{a}=$ First stage of tertiary education, first degree, medium duration; Level $5 \mathrm{~b}=$ First stage of tertiary education, short or medium duration, practical orientation; Level $6=$ Second stage of tertiary education.

Source: ILO (2012), 14. 


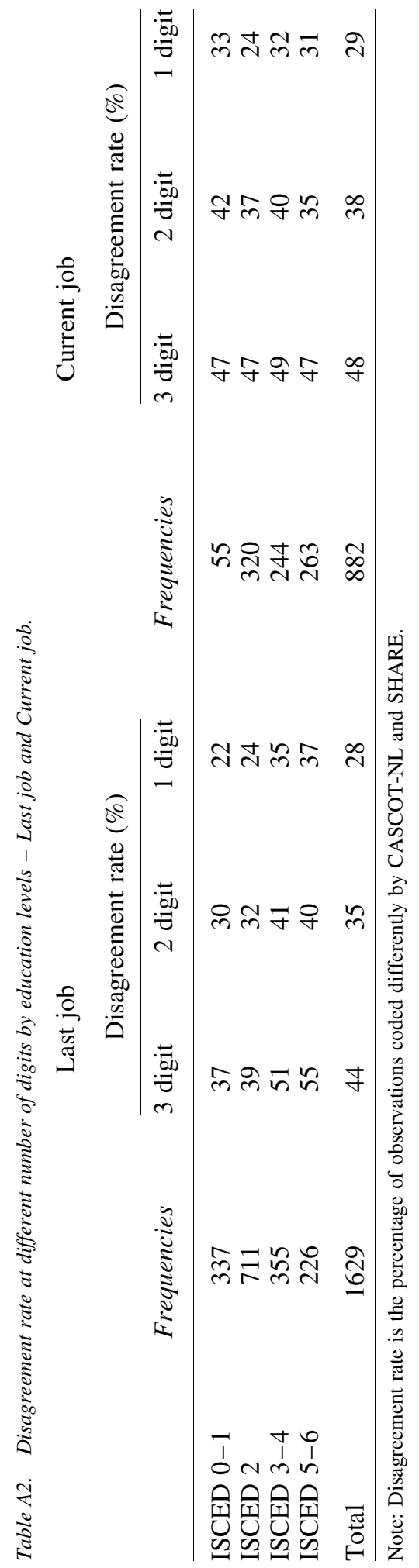




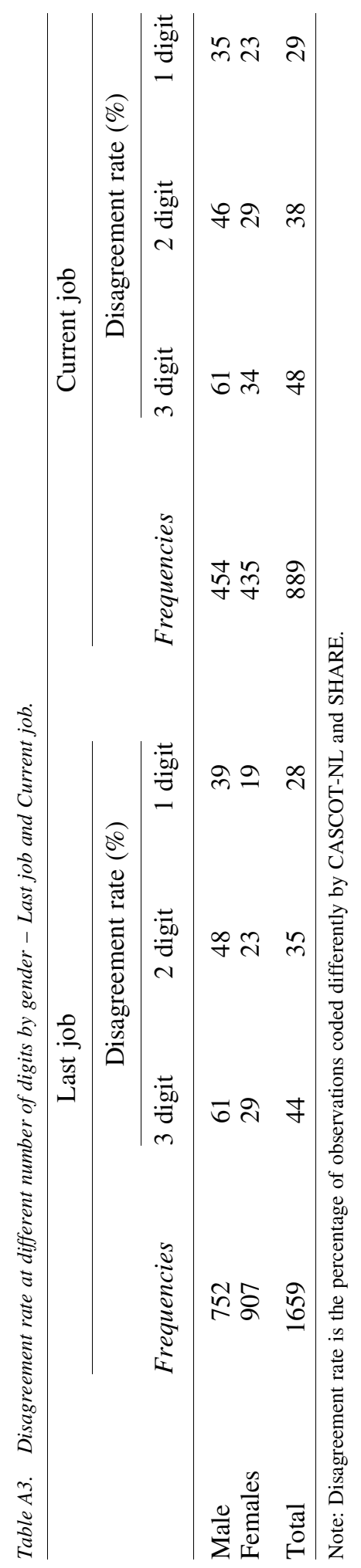


Table A4a. Disagreement rate at different number of digits by industry - Last job (sorted by disagreement rate at three digits).

\begin{tabular}{|c|c|c|c|c|}
\hline \multirow[b]{2}{*}{ Industry } & \multirow[b]{2}{*}{ Frequencies } & \multicolumn{3}{|c|}{ Disagreement rate $(\%)$} \\
\hline & & 3 digit & 2 digit & 1 digit \\
\hline Recycling & 1 & 100 & 100 & 100 \\
\hline Research and development & 5 & 80 & 60 & 40 \\
\hline $\begin{array}{l}\text { Manufacture of coke, refined petroleum } \\
\text { products and nuclear fuel }\end{array}$ & 14 & 79 & 64 & 64 \\
\hline $\begin{array}{l}\text { Manufacture of motor vehicles, trailers } \\
\text { and semi-trailers }\end{array}$ & 14 & 79 & 50 & 43 \\
\hline Electricity, gas, steam and hot water supply & 21 & 76 & 52 & 38 \\
\hline Manufacture of other nonmetallic mineral products & 8 & 75 & 63 & 63 \\
\hline Financial services and insurance & 28 & 64 & 21 & 21 \\
\hline $\begin{array}{l}\text { Public administration and defence; } \\
\text { compulsory social security }\end{array}$ & 127 & 61 & 55 & 53 \\
\hline $\begin{array}{l}\text { Sewage and refuse disposal, sanitation } \\
\text { and similar activities }\end{array}$ & 5 & 60 & 40 & 40 \\
\hline $\begin{array}{l}\text { Manufacture of basic metals, metal products } \\
\text { except machinery \& equipment }\end{array}$ & 22 & 59 & 50 & 32 \\
\hline Mining & 74 & 58 & 54 & 24 \\
\hline Computer and related activities & 7 & 57 & 57 & 57 \\
\hline $\begin{array}{l}\text { Publishing, printing and reproduction } \\
\text { of recorded media }\end{array}$ & 28 & 57 & 54 & 43 \\
\hline $\begin{array}{l}\text { Manufacture of wood and of products of } \\
\text { wood and cork, except furniture; manufacture } \\
\text { of articles of straw and plaiting materials }\end{array}$ & 9 & 56 & 44 & 44 \\
\hline Hotels and restaurants & 20 & 55 & 55 & 20 \\
\hline Recreational, cultural and sporting activities & 37 & 54 & 38 & 24 \\
\hline Transport, post, telecommunications & 66 & 53 & 45 & 38 \\
\hline $\begin{array}{l}\text { Real-estate activities; renting of machinery and } \\
\text { equipment without operator and of personal } \\
\text { and household goods }\end{array}$ & 10 & 50 & 20 & 20 \\
\hline Construction & 120 & 48 & 38 & 29 \\
\hline $\begin{array}{l}\text { Manufacture of food, tobacco, textiles, clothes, } \\
\text { bags, leather goods }\end{array}$ & 101 & 48 & 41 & 35 \\
\hline Manufacture of furniture; manufacturing NEC & 7 & 43 & 43 & 29 \\
\hline Education & 111 & 41 & 17 & 14 \\
\hline $\begin{array}{l}\text { Manufacture of electronic or electric machinery } \\
\text { and devices }\end{array}$ & 17 & 41 & 29 & 18 \\
\hline Manufacture of machinery and equipment NEC & 8 & 38 & 38 & 25 \\
\hline $\begin{array}{l}\text { Wholesale trade and commission trade, except } \\
\text { of motor vehicles and motorcycles }\end{array}$ & 34 & 38 & 35 & 29 \\
\hline Activities of membership organisation NEC & 17 & 35 & 24 & 18 \\
\hline $\begin{array}{l}\text { Sale, maintenance and repair of motor vehicles and } \\
\text { motorcycles; retail sale of automotive fuel }\end{array}$ & 17 & 35 & 35 & 24 \\
\hline Other business activities & 100 & 33 & 27 & 23 \\
\hline $\begin{array}{l}\text { Retail trade, except of motor vehicles } \\
\text { and motorcycles; repair of personal and } \\
\text { household goods }\end{array}$ & 192 & 29 & 27 & 22 \\
\hline Other service activities & 39 & 26 & 23 & 21 \\
\hline Health and social work & 211 & 25 & 21 & 19 \\
\hline Total & 1470 & 44 & 35 & 28 \\
\hline
\end{tabular}

Note: Disagreement rate is the percentage of observations coded differently by CASCOT-NL and SHARE. Industry is classified using NACE Codes, Version 4 Rev. 11993 (see http://www.top500.de/nace4-e.htm for a description of NACE Version 4 Rev. 1 and MEA 2013, pp. 32-33 for the shorter classification used in SHARE). 
Table A4b. Disagreement rate at different number of digits by industry - Current job (sorted by disagreement rate at three digits).

\begin{tabular}{|c|c|c|c|c|}
\hline \multirow[b]{2}{*}{ Industry } & \multirow[b]{2}{*}{ Frequencies } & \multicolumn{3}{|c|}{ Disagreement rate $(\%)$} \\
\hline & & 3 digit & 2 digit & 1 digit \\
\hline $\begin{array}{l}\text { Electricity, gas, steam and hot } \\
\text { water supply }\end{array}$ & 6 & 100 & 83 & 67 \\
\hline $\begin{array}{l}\text { Manufacture of motor vehicles, } \\
\text { trailers and semi-trailers }\end{array}$ & 2 & 100 & 50 & 50 \\
\hline $\begin{array}{l}\text { Manufacture of other nonmetallic } \\
\text { mineral products }\end{array}$ & 1 & 100 & 100 & 100 \\
\hline Mining & 43 & 84 & 77 & 33 \\
\hline $\begin{array}{l}\text { Manufacture of wood and of products of } \\
\text { wood and cork, except furniture; manufacture } \\
\text { of articles of straw and plaiting materials }\end{array}$ & 7 & 71 & 43 & 29 \\
\hline Construction & 50 & 68 & 44 & 38 \\
\hline Hotels and restaurants & 9 & 67 & 67 & 22 \\
\hline $\begin{array}{l}\text { Manufacture of basic metals, metal products } \\
\text { except machinery \& equipment }\end{array}$ & 3 & 67 & 67 & 33 \\
\hline Research and development & 3 & 67 & 67 & 67 \\
\hline Financial services and insurance & 15 & 60 & 27 & 20 \\
\hline $\begin{array}{l}\text { Manufacture of food, tobacco, textiles, clothes, } \\
\text { bags, leather goods }\end{array}$ & 22 & 59 & 59 & 41 \\
\hline $\begin{array}{l}\text { Real-estate activities, renting of machinery and } \\
\text { equipment without operator and of personal } \\
\text { and household goods }\end{array}$ & 12 & 58 & 42 & 42 \\
\hline Transport, post, telecommunications & 35 & 57 & 51 & 40 \\
\hline Computer and related activities & 9 & 56 & 56 & 44 \\
\hline Other business activities & 61 & 54 & 41 & 36 \\
\hline $\begin{array}{l}\text { Manufacture of coke, refined petroleum } \\
\text { products and nuclear fuel }\end{array}$ & 4 & 50 & 25 & 25 \\
\hline $\begin{array}{l}\text { Manufacture of electronic or electric } \\
\text { machinery and devices }\end{array}$ & 6 & 50 & 33 & 17 \\
\hline $\begin{array}{l}\text { Public administration and defence; } \\
\text { compulsory social security }\end{array}$ & 68 & 50 & 43 & 35 \\
\hline $\begin{array}{l}\text { Sale, maintenance and repair of motor } \\
\text { vehicles and motorcycles; retail sale } \\
\text { of automotive fuel }\end{array}$ & 13 & 46 & 38 & 23 \\
\hline Education & 107 & 41 & 19 & 16 \\
\hline Recreational, cultural and sporting activities & 25 & 40 & 32 & 20 \\
\hline Manufacture of machinery and equipment NEC & 8 & 38 & 38 & 25 \\
\hline $\begin{array}{l}\text { Retail trade, except of motor vehicles and } \\
\text { motorcycles; repair of personal and } \\
\text { household goods }\end{array}$ & 58 & 34 & 31 & 24 \\
\hline Health and social work & 173 & 33 & 30 & 28 \\
\hline $\begin{array}{l}\text { Publishing, printing and reproduction } \\
\text { of recorded media }\end{array}$ & 12 & 25 & 25 & 25 \\
\hline Other service activities & 17 & 24 & 18 & 18 \\
\hline Activities of membership organisation NEC & 7 & 14 & 14 & 14 \\
\hline Manufacture of furniture; manufacturing NEC & 3 & 0 & 0 & 0 \\
\hline $\begin{array}{l}\text { Wholesale trade and commission trade, } \\
\text { except of motor vehicles and motorcycles }\end{array}$ & 4 & 0 & 0 & 0 \\
\hline Total & 783 & 47 & 37 & 29 \\
\hline
\end{tabular}

Note: Disagreement rate is the percentage of observations coded differently by CASCOT-NL and SHARE. Industry is classified using NACE Codes, Version 4 Rev. 11993 (see http://www.top500.de/nace4-e.htm for a description of NACE Version 4 Rev. 1 and MEA 2013, pp. 32-33 for the shorter classification used in SHARE). 


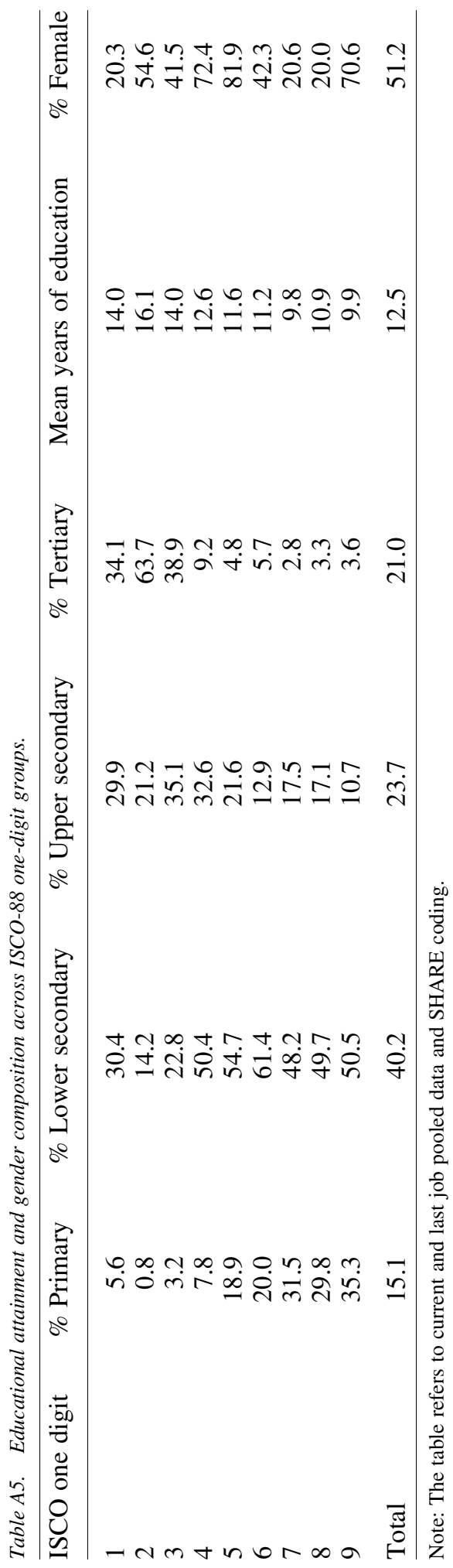




\section{References}

Autor, D. 2013. “The 'Task Approach' to Labour Markets: an Overview.” Journal of Labour Market Research 46: 185-199. Doi: http://dx.doi.org/10.1007/ s12651-013-0128-z.

Autor, D., L.F. Katz, and M.S. Kearney. 2006. "The Polarization of the US Labor Market." American Economic Review 96: 189-194. Doi: http://dx.doi.org/10.1257/ 000282806777212620.

Autor, D., F. Levy, and R.J. Murnane. 2003. "The Skill Content Of Recent Technological Change: An Empirical Exploration.” Quarterly Journal of Economics 118: 1279-1333. Doi: http://dx.doi.org/10.1162/003355303322552801.

Bethmann, A., M. Schierholz, K. Wenzig, and M. Zielonka. 2014. Automatic Coding of Occupations Using Machine Learning Algorithms for Occupation Coding in Several German Panel Surveys. In: Statistics Canada (Ed.), Beyond traditional survey taking. Adapting to a changing world. Proceedings of Statistics Canada Symposium 2014, Quebec. Available at: http://fdz.iab.de/342/section.aspx/Publikation/k151124301 (accessed October 2016).

Biemer, P.B. and L.E. Lyberg. 2003. Introduction to Survey Quality. New York: John Wiley \& Sons, Inc.

CBS (Statistics Netherlands). 2012. Coding Tool Implemented in 2012 for Coding Occupations in Social Surveys. Internal Document. The Hague: Statistics Netherlands. Cheeseman Day, J. 2014. Using an Autocoder to Code Industry and Occupation in the American Community Survey. Presentation held at the Federal Economic Statistics Advisory Committee Meeting, 13 June 2014. Available at: http://www2.census.gov/ adrm/fesac/2014-06-13_day.pdf (accessed October 2016).

Christelis, D., T. Jappelli, and M. Padula. 2010. "Cognitive Abilities and Portfolio Choice." European Economic Review 54: 18-38. Doi: http://dx.doi.org/10.1016/j. euroecorev.2009.04.001.

Commission of the European Communities. 2009. "Commission Regulation (EC) No 1022/2009 of 29 October 2009 amending Regulations (EC) No 1738/2005, (EC) No 698/2006 and (EC) No 377/2008 as regards the International Standard Classification of Occupations (ISCO)." Official Journal of the European Union, L 283/3, 30 October 2009. Available at: http://eur-lex.europa.eu/legal-content/EN/TXT/PDF/?uri=CELEX:32009R1022\&from=EN (accessed October 2016).

DESA. 2010. "Handbook on Population and Housing Census Editing." Revision 1, Series F, No 82 (Studies in Methods (Ser. F)), United Nations Statistics Division. New York: United Nations Publication. Available at: http://unstats.un.org/unsd/publication/ SeriesF/seriesf_82rev1e.pdf (accessed October 2016).

Elias, P., K. Halstead, and K. Prandy. 1993. Computer-Assisted Standard Occupational Coding. London: HMSO.

Elias, P. 1997. "Occupational Classification (ISCO-88). Concepts, Methods, Reliability, Validity and Cross-National Comparability." OECD Labour Market and Social Policy Occasional Papers No. 20, OECD Publishing. Doi: http://dx.doi.org/10.1787/ 304441717388. 
Ellison, R. 2014. Demonstration of Performance of CASCOT 5.0. Presentation held at the CASCOT: Occupational Coding in Multi-national Surveys Workshop, 10-11 April 2014 Venice. Available at: http://dasish.eu/dasishevents/cascotworkshop/programmepres/ (accessed 15 April, 2014).

Feenstra, R.C. and G.H. Hanson. 1996. "Globalization, Outsourcing, and Wage Inequality." American Economic Review 86: 240-245. Available at: http://www. jstor.org/stable/2118130.

Fletcher, J.M., J.L. Sindelar, and S. Yamaguchi. 2011. "Cumulative Effects of Job Characteristics on Health." Health Economics 20: 553-570. Doi: http://dx.doi.org/ 10.1002/hec.1616.

Ganzeboom, H. 2008. Occupation Coding: Do's And Dont's. Version 2, 2 August 2008. Available at: http://www.gesis.org/fileadmin/upload/dienstleistung/daten/umfragedaten/ issp/members/codinginfo/ISCO-coding_dos_donts_HG2008.pdf (accessed October 2016).

Goos, M. and A. Manning. 2007. "Lousy and Lovely Jobs: The Rising Polarization of Work in Britain." Review of Economics and Statistics 89: 118-133. Doi: http://dx.doi. org/10.1162/rest.89.1.118.

Hartog, J. 2000. "Over-Education and Earnings: Where Are We, Where Should We Go?" Economics of Education Review 19: 131-147. Doi: http://dx.doi.org/10.1016/ S0272-7757(99)00050-3.

Hoffmann, E., P. Elias, B. Embury, and R. Thomas. 1995. What Kind Of Work Do You Do? Data Collection and Processing Strategies When Measuring "Occupation" for Statistical Surveys and Administrative Records. ILO working paper, N.95-1. Geneva: ILO. Available at: http://www.ilo.org/global/statistics-and-databases/WCMS_087880/ lang-en/index.htm (accessed October 2016).

Jackle, A. 2008. "Dependent Interviewing: Effects on Respondent Burden and Efficiency of Data Collection.” Journal of Official Statistics 24: 411-430.

Jones, R. and P. Elias. 2004. "CASCOT: Computer-Assisted Structured Coding Tool." Coventry: Warwick Institute for Employment Research, University of Warwick.

ILO. 2014. ISCO: International Standard Classification of Occupations. Available at: http://www.ilo.org/public/english/bureau/stat/isco/ (accessed 3 October, 2016).

ILO. 2012. International Standard Classification of Occupations: Structure, Group Definitions and Correspondence tables. Vol. 1. Geneva: ILO. Available at: http:// www.ilo.org/wcmsp5/groups/public/_dgreports/_dcomm/_-publ/documents/ publication/wcms_172572.pdf (accessed October 2016).

ILO. 2010. Measuring the Economically Active in Population Censuses: A Handbook. Studies in Methods Series F, No. 102. New York: ILO and UN.

Leist, A.K., M.M. Glymour, J.P. Mackenbach, F.J. van Lenthe, and M. Avendano. 2013. "Time Away from Work Predicts Later Cognitive Function: Differences by Activity During Leave." Annals of Epidemiology 23: 455-462. Doi: http://dx.doi.org/10.1016/j. annepidem.2013.05.014.

Leuven, E. and H. Oosterbeek. 2011. "Overeducation and Mismatch in the Labor Market." In Handbook of the Economics of Education, edited by E. Hanushek, S. Machin and L. Woessmann, 283-326. Amsterdam: Elsevier. 
MEA. 2013. SHARE Release Guide 2.6.0. Waves 1 \& 2. Munich: publisher. Available at: Munich Center for the Economics of Ageing (MEA) at the Max Planck Institute for Social Law and Social Policy (MPISOC) publishing. (accessed October 2016).

Moscarini, G. and K. Thomsson. 2007. "Occupational and Job Mobility in the US." The Scandinavian Journal of Economics 109: 807-836. Doi: http://dx.doi.org/10.1111/j. 1467-9442.2007.00510.x.

Perales, F. 2014. "How Wrong Were We? Dependent Interviewing, Self-Reports and Measurement Error in Occupational Mobility in Panel Surveys." Longitudinal and Life Course Studies 4: 299-316. Doi: http://dx.doi.org/10.14301/llcs.v5i3.295.

Ravesteijn, B., H. van Kippersluis, and E. van Doorslaer. 2013. The Wear and Tear on Health: What is the Role of Occupation? Tinbergen Institute Discussion Paper 13-143. Amsterdam: Tinbergen Institute. Available at: http://papers.tinbergen.nl/13143.pdf (accessed October 2016).

Rose, D. and E. Harrison. 2007. "The European Socio-Economic Classification: A New Social Class Schema For Comparative European Research." European Societies 9: 459-490. Doi: http://dx.doi.org/10.1080/14616690701336518.

Tijdens, K.G. 2014a. "Drop-Out Rates During Completion of an Occupation Search Tree in Web-Surveys." Journal of Official Statistics 30: 23-43. Doi: http://dx.doi.org/ 10.2478/jos-2014-0002.

Tijdens, K.G. 2014b. Reviewing the Measurement and Comparison of Occupations Across Europe. AIAS Working Paper 149. Amsterdam: University of Amsterdam. Available at: http://dare.uva.nl/record/1/432281 (accessed October 2016).

United Nations. 2007. "Updating the International Standard Classification of Occupations (ISCO): Summary of major changes between ISCO-88 and ISCO-08 (Feb 2007 draft)." Paper for discussion by the Expert Group on International Economic and Social Classifications, New York, 16-18 April 2007. Available at: http://unstats.un.org/unsd/ class/intercop/expertgroup/2007/AC124-11.PDF (accessed October 2016).

United Nations (UN). 2014. National Classifications. Available at: http://unstats.un.org/ unsd/cr/ctryreg/ctrylist2.asp (accessed March 2015).

Westerman, S. 2014. "CBS and CASCOT: tuning CASCOT for improved performance." Presentation held at the CASCOT: Occupational Coding in Multi-national Surveys Workshop, 10-11 April 2014, Venice. Available at: http://dasish.eu/dasishevents/ cascotworkshop/programmepres/ (accessed 15 April, 2014).

Wilcoxon, F. 1945. "Individual Comparisons by Ranking Methods." Biometrics 1: 80-83. Available at: http://www.jstor.org/stable/3001968.

Wooldridge, J.M. 2010. Econometric Analysis of Cross Section and Panel Data. Cambridge, MA: MIT Press.

Received December 2014

Revised April 2016

Accepted July 2016 